\title{
End of the slo-mo?
}

\author{
As the world's leaders are negotiating climate change mitigation in Paris, a strong El Niño brings the \\ warmest year on record. After a decade and a half of slow warming and slow policy progress, 2015 may \\ bring an acceleration of both.
}

The climate talks in Paris carry high hopes. Following repeated rounds of annual negotiations that brought little agreement on how best to tackle climate change, this time many countries submitted plans for reducing their greenhouse gas emissions ahead of the meeting. These plans are probably not ambitious enough to avoid dangerous - or at least expensive - climate change, but they do, finally, signal progress.

The negotiations may receive an unexpected push from the climate system. An exceptionally strong El Niño is expected for the coming winter. If the event is as powerful as forecast, it will ratchet up global warming by releasing heat from the ocean to the atmosphere and upset weather patterns worldwide ${ }^{1}$.

2015 is already on track for being declared the warmest year since records began $^{2}$, within the warmest five-year period. Indeed, this year the Earth may reach the half-way point to the widely used climate policy target of keeping warming to less than $2{ }^{\circ} \mathrm{C}$ above pre-industrial temperatures. With a strong El Niño brewing in the Pacific, the end of the year is unlikely to bring relief: the warm spike associated with the most recent 'super' El Niño in 1997/98 stands out in the global mean temperature record.

Media reports of El Niño impacts and record temperatures in 2015 are putting additional pressure on the negotiators in Paris - not unreasonably given that climate change may well have played a role in the

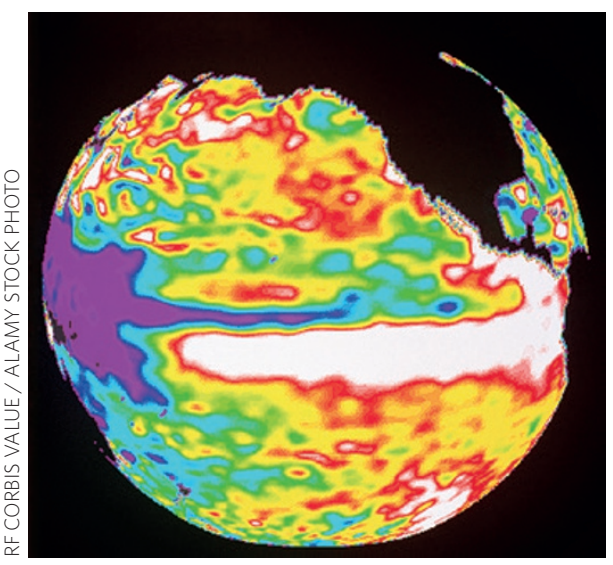

A strong El Niño is expected for the coming winter. unusual evolution of the 2015 El Niño event $^{3}$. And faced with the extra security after the Paris attacks, negotiators may be giving serious thought to the notion that climate change may be implicated in conflict, for example, in Syria ${ }^{4}$.

The Paris meeting is the twenty-first in a long string of Conferences of the Parties since the 1992 United Nations Framework Convention on Climate Change; the past few years have been characterized not only by slow global warming but also by rather modest progress in policy agreements. There

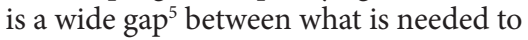
rapidly transform global energy systems away from carbon-emitting technologies and what is being done.

This discrepancy could at least partly result from the use of integrated assessment models in policy advice, suggest two Commentaries that are part of a joint focus presented by Nature Geoscience and Nature Climate Change (http://www.nature.com/ ngeo/focus/budgeting-for-climate-change/ index.html). These models are geared to optimizing cost-benefit targets by simulating climate and economy together. Thereby, they focus on gross domestic product, rather than considering a broader definition of wellbeing ${ }^{6}$. Integrated assessment models have also made it possible to disguise the urgency of rapid economic transformation, by allowing the calculation of carbon budgets with overly optimistic assumptions: the scenarios that keep warming below the $2{ }^{\circ} \mathrm{C}$ target necessitate the removal of substantial amounts of greenhouse gases from the atmosphere in the near future ${ }^{7}$, requiring technologies whose viability at a useful scale is entirely unproven ${ }^{8}$.

In their scientific assessment of the $2{ }^{\circ} \mathrm{C}$ target - a goal that entered the arena of climate change as a political compromise, rather than a science-based guideline Reto Knutti and colleagues ${ }^{9}$ conclude that global mean surface temperature is the best available proxy measure for climate change. But how much warming should be tolerated is an ethical and political question that cannot be decided by science alone. However, scientific information needs to be taken into account. For example, Kate Ricke and colleagues ${ }^{10}$ discuss emerging evidence that a number of sectors - including the croplands for staple foods and coral reefs show particularly strong deterioration around or before a warming of $2{ }^{\circ} \mathrm{C}$ is reached. They argue for ambitious emissions targets early on, when the potential gains from a strong policy are highest.

Ultimately, however, the key point is to start mitigation now, rather than later. The final target can be adjusted as momentum builds ${ }^{9}$. The Paris climate talks, with the countries' promises on the table, may deliver just that: actions on climate change. These actions will almost certainly need to be tightened and modified as they are put into practice. Hopefully, they will also be independently monitored.

There is some reason for optimism. In 2014 and now in 2015, the world economy appears, for once, to have decoupled from carbon dioxide emissions ${ }^{11}$. Economic growth did not go hand in hand with steep emissions increases, probably as a result of structural changes in the energy systems of some countries. If so, the negotiators in Paris may only have to reinforce and accelerate existing trends, rather than turn the tide.

The Kyoto Protocol - a significant step in climate change policy, despite its shortcomings - was adopted in December 1997, in the midst of the most recent super El Niño. Perhaps that bodes well for the negotiations in Paris.

\footnotetext{
References

1. El Niño expected to strengthen further: high impacts, unprecedented preparation. World Meteorological Organization (16 November 2015); http://go.nature.com/TFs8Zp

2. WMO: 2015 likely to be warmest on record, 2011-2015 warmest five year period. World Meteorological Organization (25 November 2015); http://go.nature.com/ua8JqV

3. McPhaden, M. J. Nature Clim. Change 5, 791-795 (2015).

4. Kelly, C. P., Mohtadi, S., Cane, M. A., Seager, R. \& Kushnir, Y. Proc. Natl Acad. Sci. USA 112, 3241-3246 (2015).

5. Frame, D. J., Macey, A. H. \& Allen, M. R. Nature Geosci. 7, 692-693 (2014).

6. Hasselmann, K. et al. Nature Geosci. 8, 895-898 (2015).

Anderson, K. Nature Geosci. 8, 898-900 (2015)

8. Smith, P. Nature Clim. Change http://dx.doi.org/10.1038/ nclimate2870 (2015).

9. Knutti, R., Rogelj, J., Sedláček, J. \& Fischer, E. M. Nature Geosci. 9, 13-18 (2016).

10. Ricke, K. L., Moreno-Cruz, J. B., Schewe, J., Levermann, A. \& Caldeira, K. Nature Geosci. 9, 5-6 (2016).

11. Jackson, R. B. et al. Nature Clim. Change http://dx.doi.org/10.1038/ nclimate2892 (2015).
}

Published online: 7 December 2015 